Original article

\title{
ASSESSMENT OF SUBCLINICAL INNER EAR DYSFUNCTION IN PSORIATIC ARTHRITIS PATIENTS
}

\author{
Hager Nabil Bayoumi Ahmed ${ }^{1}$, Omaima Zakaria Shehata ${ }^{2}$, Soha Abd-el Raouf Mekki \\ Marwa Hammad ${ }^{1}$ \\ 1Rheumatology and Rehabilitation Department, Helwan General Hospital, Cairo, Egypt \\ 2Rheumatology and rehabilitation Department, faculty of Medicine, Zagazig University, Zagazig, \\ Egypt \\ 3Audiovestibular Medical Unit, ENT Department, Faculty of Medicine, Zagazig University, \\ Zagazig, Egypt
}

\section{Corresponding Author: \\ Hager Nabil Bayoumi \\ Ahmed \\ Rheumatology and \\ Rehabilitation Department, \\ Helwan General Hospital, \\ Cairo, Egypt \\ hagernabil11@gmail.com}

\section{Submit Date 2019-02-16 \\ Revise Date 2019-03-09 \\ Accept Date 2019-03-11}

\section{INTRODUCTION}

soriasis is a chronic inflammatory skin condition, which has a multifactorial basis. Hyperproliferation and abnormal differentiation of epidermal keratinocytes is a hallmark of the disease (1). Psoriatic arthritis is a chronic inflammatory

\section{ABSTRACT}

Introduction: In patients with spondyloarthropathies, underlying autoimmune mechanisms and vasculitis may affect audiovestibular system. In previously presented studies, presence of sensory neural hearing loss (SNHL) was detected in some patients with PsA.

Aim: The aim of this study was early detection of subclinical inner ear affection in psoriatic arthritis patients.

Methods: a case-control study was carried out in Rheumatology and Rehabilitation Department and Audiovestibular unit, Faculty of Medicine, Zagazig University Hospitals. The sample size was calculated to be 32 divided into 2 groups: 16 psoriatic arthritis patients (Group 1) and 16 apparently healthy age and sex matched controls (Group 2). Psoriatic arthritis patients were gathered according to CASPAR classification criteria for psoriatic arthritis. All participants underwent an otoscopic examination \& pure tone audiometry (PTA) with air conduction testing from 250 through $8000 \mathrm{~Hz}$ delivered through headphone TDH39 and bone conduction testing from 500 through $4000 \mathrm{~Hz}$, bone conduction stimulus will be delivered via bone conduction vibrator model B71 on mastoid using ascending, descending techniques and speech audiometry.

Results: Significant differences in the pure-tone audiogram values at 8000 $\mathrm{Hz}$ and acoustic reflex at $4000 \mathrm{~Hz}$ detected in patients with PsA also tympanometric values were statistically different relative to control group indicating involvement of the functions of the inner ear. There is significant difference between PsA and control group regarding acoustic reflex in contralateral ear both right and left ear at $4000 \mathrm{~Hz}$. No significant difference between PsA and control group regarding speech reception threshold and Speech discrimination in both right and left ear.

Conclusion: this study provides evidence suggesting the presence of subclinical SNHL in PsA patients denoting necessity of audiological assessment of PsA patients.

Keywords: Psoriatic arthritis, Inner ear dysfunction, Audiometry, Speech audiometry

arthropathy, it is encountered in nearly $30 \%$ of patients diagnosed with psoriasis (2).

Psoriatic arthritis may be triggered by unknown environmental agent in genetically susceptible individuals and understanding its etiology may highlight pathways for 
intervention and allow risk prediction in the future (3).

Manifestations of psoriatic arthritis include a combination of axial disease , peripheral arthritis and specific features such as enthesitis and dactylitis(4). Extraarticular manifestations of psoriatic arthritis occur infrequently and it includes: iridocyclitis which is characterized by acute onset over 1-2 days (5), urethritis and bowel involvement (6) as well as cardiac involvement (7).

In patients with spondyloarthropathy, underlying autoimmune mechanisms and vasculitis may affect audiovestibular system (8).

In previously presented studies, presence of sensory neural hearing loss (SNHL) was detected in some patients with PsA. In these studies, inner ear dysfunction was more frequent in high-frequency hearing thresholds (9). Monitoring and targeting ear affection in PsA is not a common practice. So the aim of our study was to detect the presence of subclinical inner ear affection as these patients may benefit from early detection and follow up.

\section{SUBJECTS AND METHODS}

"Written informed consent was obtained from all participants and the study was approved by the research ethical committee of Faculty of Medicine, Zagazig University. The work has been carried out in accordance with The Code of Ethics of the World Medical Association (Declaration of Helsinki) for studies involving humans."

\section{Study design and subjects:}

This case-control study was carried out in Rheumatology and Rehabilitation department and audiovestibular unit, Faculty of Medicine, Zagazig University Hospitals. The sample size was calculated to be 32 divided into 2 groups: 16 psoriatic arthritis patients (Group 1) and 16 apparently healthy age and sex matched controls (Group 2). Psoriatic arthritis patients were gathered according to CASPAR classification criteria for psoriatic arthritis (10). Exclusion criteria included: patients with other spondyloarthropathies, autoimmune diseases, others diseases affecting hearing or patients receiving ototoxic drugs. Patients with history of preexisting inner ear pathology were excluded.

\section{Musculoskeletal assessment:}

All joints of the body and spine were examined thoroughly by inspection, palpation and Range of motion.

\section{Audiological assessment:}

All participants underwent an otoscopic examination \& pure tone audiometry (PTA) with air conduction testing from 250 through $8000 \mathrm{~Hz}$ delivered through headphone TDH39 and bone conduction testing from 500 through $4000 \mathrm{~Hz}$, bone conduction stimulus will be delivered via bone conduction vibrator model B71 on mastoid using ascending descending techniques, speech audiometry: speech reception threshold (SRT) using Arabic spondee word (11) and word discrimination score (SD \%) using Arabic phonetically balanced word (12), Immittancemetry including Tympanometry will be done at varying pressure ranging from +200 to -400 $\mathrm{mm} \mathrm{H} 2 \mathrm{O}$ (single-component, singlefrequency) with a probe tone of $226 \mathrm{~Hz}$ and Acoustic reflex threshold, for the ipsilateral and contralateral elicited reflexes using pure tones at frequencies 500, 1000, 2000, and $4000 \mathrm{~Hz}$.

\section{Lab investigations:}

The following lab tests were done Complete blood picture (CBC) ,Erythrocyte sedimentation rate (ESR), Highly sensitive C-reactive protein (CRP) ,Liver function tests( ALT, AST and albumin),Kidney function tests( BUN and serum creatinine ), Rheumatoid factor, Fasting blood sugar and 2 hours postprandial blood sugar .

\section{Statistical Methods}

The collected data were coded, entered, presented, and analyzed by computer using a data base software program, Statistical Package for Social Science (SPSS) (version 20, SPSS Inc., Chicago, IL).

\section{RESULTS}

\section{Demographic, clinical \& laboratory characteristics}

Table (1) shows the demographic, clinical,measures and laboratory characteristics of our patients. The mean age of our patients was $44.31 \pm 6.91$, most 
of our patients were females, mean CPDAI was $4.75 \pm 1.57$.

\section{Air \& Bone conduction thresholds}

Table 1 shows significant difference between PsA and control group regarding air conduction thresholds at $8000 \mathrm{~Hz}$ in both right and left ear. Table 2 shows no significant difference between PsA and control group regarding bone conduction thresholds in both right and left ear.

3.3. Acoustic reflex, Mean speech reception threshold, and Speech discrimination:

Table 4 shows significant difference between PsA and control group regarding acoustic reflex in contralateral ear both right and left ear at $4000 \mathrm{~Hz}$. Table 5 shows no significant difference between PsA and control group regarding SRT and SDin both right and left ear.

\section{4.: Types of tympanometry:}

Figure 1 shows that most of PsA and control groups right ear were type A tympanometry. Figure 2 shows that most of PsA and control groups left ear were type A tympanometry. Table 5 shows significant difference between PsA and control groups regarding type of right tympanometry as PsA group had more abnormal types. Table 6 shows no significant difference between PsA and control groups regarding type of left tympanometry.

Table 6 shows significant difference between PsA and control groups regarding type of right tympanometry as PsA group had more abnormal types

Table 1 Demographic, clinical and laboratory characteristics of PsA patients and control group

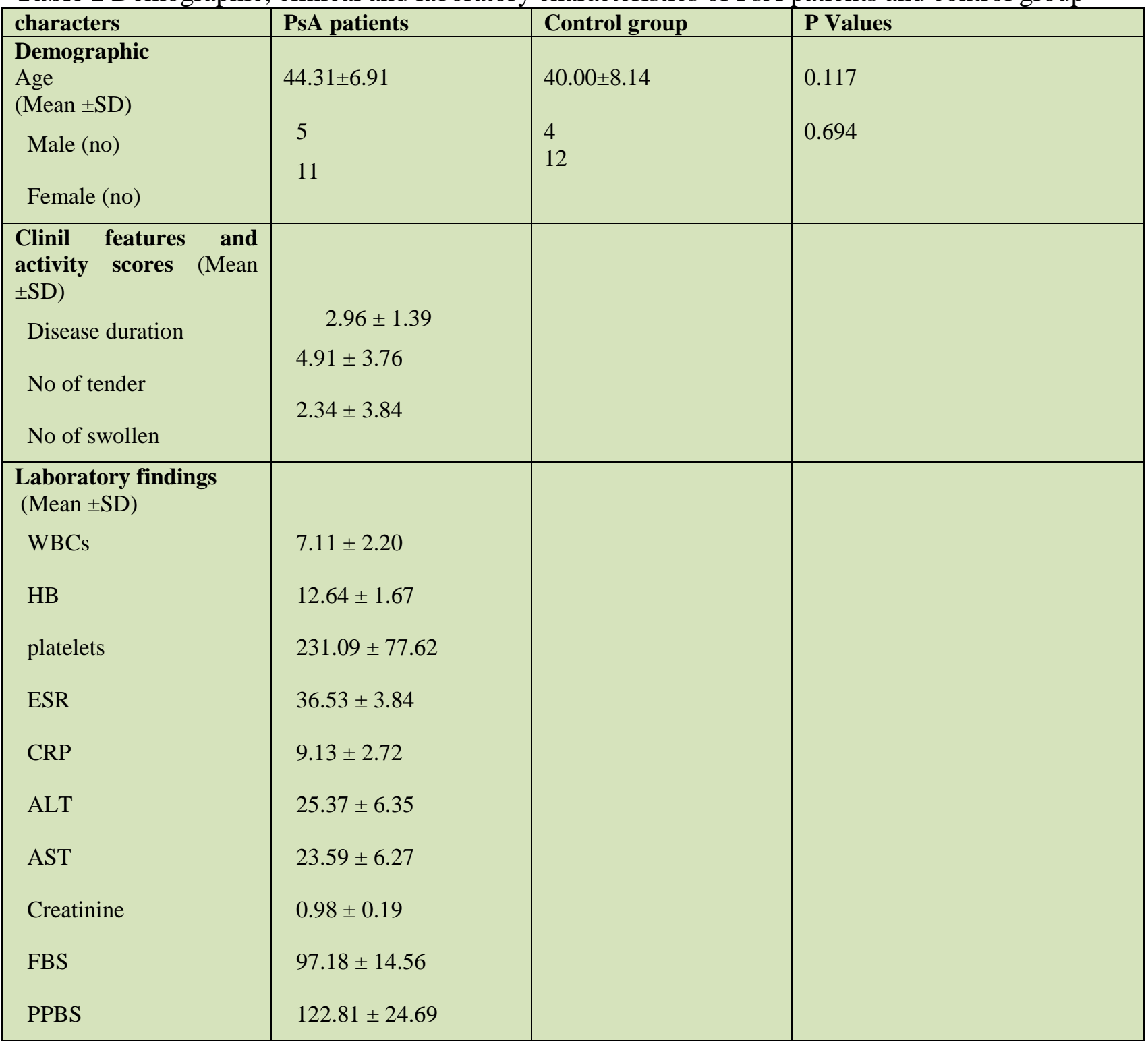

PsA: psoriatic arthritia, SD: standard deviation , No: Number. 
WBCs: white blood cells, Hb: hemoglobin, ESR: Erythrocyte sedimentation rate, CRP: C-reactive protein, ALT : Alanine Aminotransferase, AST: aspartate aminotransferase, FBS: fasting blood sugar, PPBS: postprandial blood sugar.

Table 2 Air conduction thresholds in pure tone audiometry $(250-8000 \mathrm{~Hz})$ for

PsA patients and healthy controls

\begin{tabular}{|l|l|l|l|}
\hline $\begin{array}{l}\text { Test Frequency } \\
(\mathbf{H z})\end{array}$ & $\begin{array}{l}\text { PsA group } \\
\text { mean } \pm \text { SD }(\mathbf{d B})\end{array}$ & $\begin{array}{l}\text { control group } \\
\text { mean } \pm \text { SD }(\mathbf{d B})\end{array}$ & P value \\
\hline Right ear & & & \\
\hline $250 \mathrm{HZ}$ & $16.25 \pm 5$ & $14.62 \pm 4.93$ & 0.362 \\
$500 \mathrm{~Hz}$ & $16.25 \pm 6.7$ & $13.68 \pm 3.78$ & 0.193 \\
$1000 \mathrm{~Hz}$ & $15.68 \pm 5.18$ & $13.87 \pm 5.17$ & 0.330 \\
$2000 \mathrm{~Hz}$ & $16.68 \pm 5.1$ & $16.31 \pm 5$ & 0.835 \\
$4000 \mathrm{~Hz}$ & $19.43 \pm 6.06$ & $16.25 \pm 4.65$ & 0.106 \\
$8000 \mathrm{~Hz}$ & $26.25 \pm 20.21$ & $12.5 \pm 5.16$ & $\mathbf{0 . 0 1 7}$ \\
\hline$\underline{\mathrm{Left} \mathrm{ear}}$ & & & \\
$250 \mathrm{~Hz}$ & $17.18 \pm 6.8$ & $18.18 \pm 5.94$ & 0.662 \\
$500 \mathrm{~Hz}$ & $18.31 \pm 6.24$ & $16.06 \pm 4.43$ & 0.249 \\
$1000 \mathrm{~Hz}$ & $17.68 \pm 6.81$ & $16.56 \pm 5.91$ & 0.621 \\
$2000 \mathrm{~Hz}$ & $16.06 \pm 5.23$ & $14.25 \pm 5.33$ & 0.340 \\
$4000 \mathrm{~Hz}$ & $20.06 \pm 8.72$ & $17.18 \pm 5.46$ & 0.273 \\
$8000 \mathrm{~Hz}$ & $26.56 \pm 20.06$ & $15.18 \pm 7.01$ & $\mathbf{0 . 0 4 6}$ \\
\hline
\end{tabular}

PsA: psoriatic arthritia, Hz: Hertz, SD: standard deviation , dB: decibel. * Significant

Table 3 Bone conduction thresholds in pure tone audiometry ( $250-8000 \mathrm{~Hz}$ ) for PsA patients and healthy controls

\begin{tabular}{|l|l|l|l|}
\hline $\begin{array}{l}\text { Test Frequency } \\
(\mathbf{H z})\end{array}$ & $\begin{array}{l}\text { PsA group } \\
\text { mean } \pm \text { SD }(\mathbf{d B})\end{array}$ & $\begin{array}{l}\text { control group } \\
\text { mean } \pm \text { SD }(\mathbf{d B})\end{array}$ & P Values \\
\hline$\underline{\text { Right ear }}$ & $15.00 \pm 4.47$ & $13.68 \pm 3.78$ & \\
$500 \mathrm{~Hz}$ & $14.43 \pm 5.20$ & $13.87 \pm 5.17$ & 0.378 \\
$1000 \mathrm{~Hz}$ & $15.18 \pm 5.08$ & $16.31 \pm 5.00$ & 0.761 \\
$2000 \mathrm{~Hz}$ & $17.87 \pm 6.77$ & $16.12 \pm 4.70$ & 0.533 \\
$4000 \mathrm{~Hz}$ & & & \\
\hline$\underline{\mathrm{Left} \mathrm{ear}}$ & $16.31 \pm 4.94$ & $15.43 \pm 4.89$ & 0.619 \\
$500 \mathrm{~Hz}$ & $16.06 \pm 5.72$ & $15.93 \pm 6.32$ & 0.954 \\
$1000 \mathrm{~Hz}$ & $14.87 \pm 5.69$ & $13.62 \pm 5.15$ & 0.533 \\
$2000 \mathrm{~Hz}$ & $16.56 \pm 8.31$ & $16.56 \pm 5.39$ & 1.000 \\
$4000 \mathrm{~Hz}$ & &
\end{tabular}

PsA: psoriatic arthritia, Hz: Hertz, SD: standard deviation , dB: decibel. 
Table 4 Acoustic reflex ( $500-4000 \mathrm{~Hz}$ ) for PsA patients and healthy controls

\begin{tabular}{|c|c|c|c|}
\hline $\begin{array}{l}\text { Test Frequency } \\
(\mathrm{Hz})\end{array}$ & $\begin{array}{l}\text { Mean } \pm \text { standard } \\
\text { deviation ( dB ) } \\
\text { PsA group }\end{array}$ & $\begin{array}{l}\text { Mean } \pm \text { standard } \\
\text { deviation }(\mathrm{dB}) \\
\text { control group }\end{array}$ & P Values \\
\hline \multicolumn{4}{|l|}{ Ipsilateral ear } \\
\hline $500 \mathrm{~Hz}$ & $85.31 \pm 1.25$ & $85.62 \pm 1.70$ & 0.559 \\
\hline $1000 \mathrm{~Hz}$ & $85.31 \pm 1.25$ & $85.62 \pm 1.70$ & 0.559 \\
\hline $2000 \mathrm{~Hz}$ & $85.31 \pm 1.25$ & $85.62 \pm 1.70$ & 0.559 \\
\hline $4000 \mathrm{~Hz}$ & $86.87 \pm 4.03$ & $85.62 \pm 1.70$ & 0.262 \\
\hline \multicolumn{4}{|l|}{ ( Left ) } \\
\hline $500 \mathrm{~Hz}$ & $85.31 \pm 1.25$ & $85.62 \pm 1.70$ & 0.559 \\
\hline $1000 \mathrm{~Hz}$ & $85.31 \pm 1.25$ & $85.62 \pm 1.70$ & 0.559 \\
\hline $2000 \mathrm{~Hz}$ & $85.31 \pm 1.25$ & $85.62 \pm 1.70$ & 0.559 \\
\hline $4000 \mathrm{~Hz}$ & $87.81 \pm 4.46$ & $85.62 \pm 1.70$ & 0.077 \\
\hline \multicolumn{4}{|l|}{$\begin{array}{l}\text { Contralateral ear } \\
\text { (Right })\end{array}$} \\
\hline $500 \mathrm{~Hz}$ & $87.81 \pm 3.14$ & $89.37 \pm 1.70$ & 0.091 \\
\hline $1000 \mathrm{~Hz}$ & $88.75 \pm 3.41$ & $89.37 \pm 1.70$ & 0.518 \\
\hline $2000 \mathrm{~Hz}$ & $89.68 \pm 4.26$ & $89.37 \pm 1.70$ & 0.788 \\
\hline $4000 \mathrm{~Hz}$ & $93.12 \pm 5.73$ & $89.37 \pm 1.70$ & $0.022 *$ \\
\hline$\frac{\text { Contralateral }}{(\text { Left })}$ & & & \\
\hline $500 \mathrm{~Hz}$ & $88.12 \pm 3.59$ & $89.37 \pm 1.70$ & 0.219 \\
\hline $1000 \mathrm{~Hz}$ & $89.37 \pm 3.59$ & $89.37 \pm 1.70$ & 1.000 \\
\hline $2000 \mathrm{~Hz}$ & $89.68 \pm 4.64$ & $89.37 \pm 1.70$ & 0.802 \\
\hline $4000 \mathrm{~Hz}$ & $94.37 \pm 7.27$ & $89.37 \pm 1.70$ & $0.016^{*}$ \\
\hline
\end{tabular}

PsA: psoriatic arthritia, Hz: Hertz, SD: standard deviation, dB: decibel. * Statistical Significance $>0.05$

Table 5 Mean speech Reception thresholds ( SRT ) and Speech discrimination (SD) values for PsA patients and healthy controls

\begin{tabular}{|c|c|c|c|}
\hline & $\begin{array}{c}\text { PsA group } \\
\text { mean } \pm \text { SD }(\mathbf{d B})\end{array}$ & $\begin{array}{c}\text { control group } \\
\text { mean } \pm \text { SD }(\mathbf{d B})\end{array}$ & P Values \\
\hline$\underline{\text { Right ear }}$ & $13.75 \pm 4.28$ & $11.87 \pm 3.59$ & 0.190 \\
SRT ( dB ) & $98.5 \pm 2.87$ & $99.00 \pm 1.78$ & 0.559 \\
SD (\%) & $15.62 \pm 5.43$ & $13.12 \pm 4.42$ & \\
\hline Left ear & $97.75 \pm 2.91$ & $98.75 \pm 1.91$ & 0.164 \\
SRT ( dB ) & & & 0.260 \\
\hline
\end{tabular}

PsA: psoriatic arthritia, SD: standard deviation , dB: decibel , SRT: speech Reception thresholds, SD: Speech discrimination. 
Figure 1 types of right tympanometry in PsA patients and Healthy controls

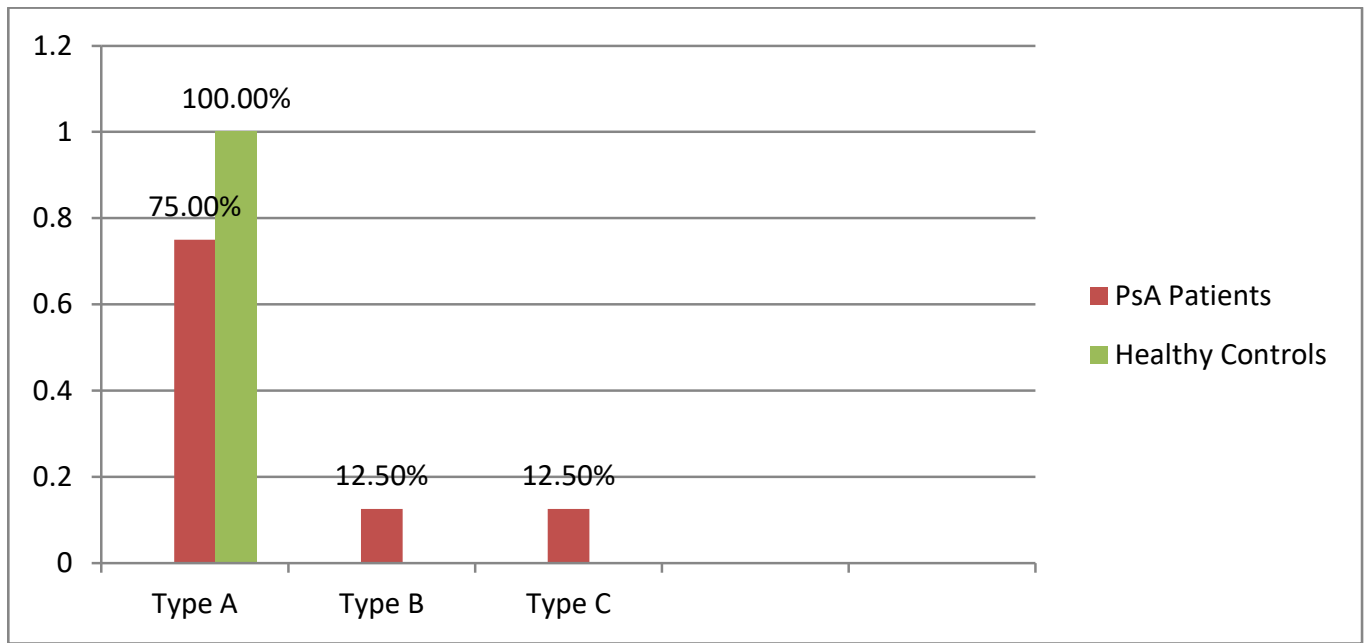

Figure 2 types of Left tympanometry in PsA patients and Healt hy controls

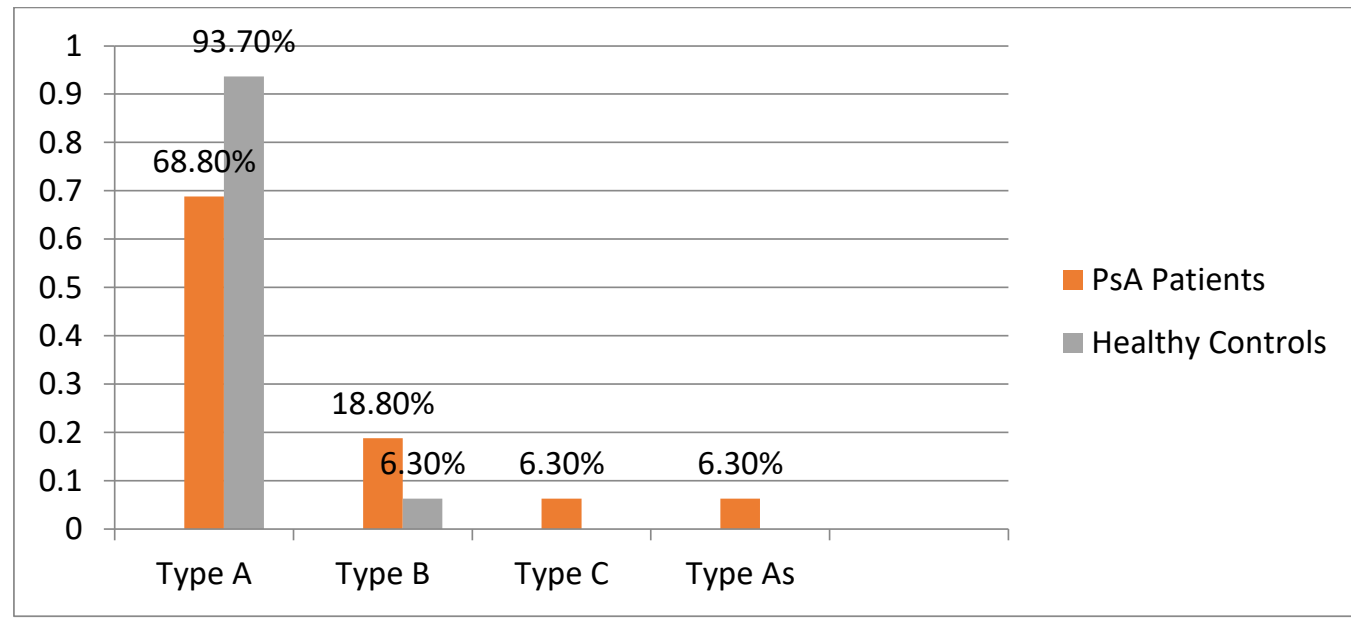

\section{DISCUSSION}

Psoriatic arthritis (PsA) is a chronic inflammatory arthropathy of peripheral joints, spine and enthesis organs. It is characterized by various subtypes and variable clinical course and results usually by a chronic and progressive process. (13). Inner ear is sensitive to autoimmune pathologies. Consequently, in autoimmune diseases, SNHLs can manifest themselves before emergence of systemic symptoms (14). Hearing losses have been reported in many diseases caused by autoimmune and autoinflammatory disorders, including rheumatoid arthritis, psoriatic arthritis, inflammatory bowel disease and ankylosing spondylitis (15).
Pure tone audiometry (PTA) is the key hearing test used to identify hearing threshold levels and provide a basis for diagnosis and management, it relies on patient responses to pure tone stimuli. PTA only measures audibility thresholds, rather than other aspects of hearing such as sound localization and speech recognition. PTA uses both air and bone conduction audiometry, the type of loss can also be identified via the air-bone gap. Although PTA has many clinical benefits, it is not perfect at identifying all losses, such as 'dead regions' of the cochlea and neuropathies such as auditory processing disorder (16). In our study patient with PsA 
were compared with the control group, we could not find a statistically significant difference for mean pure-tone measurements. However, threshold values of air conduction at $8000 \mathrm{~Hz}$ frequency in the patient group were significantly different when compared with the control group. In a study performed on patients with PsA, hearing loss was encountered in $60 \%$ of the patients, while in the control group in only $5 \%$ of the control subjects alterations in audiograms were detected. The authors concluded that high-frequency thresholds were more severely affected but also similarly hearing acuity at high-frequency thresholds over $8000 \mathrm{~Hz}$ was not evaluated (17).

In a previous study performed in 2016 there was significant differences in the pure-tone audiogram values at $4000 \mathrm{~Hz}$ and $6000 \mathrm{~Hz}$ and DPOAE values at $3000 \mathrm{~Hz}$ and $4000 \mathrm{~Hz}$ detected in patients with PsA demonstrate involvement of the functions of the inner ear (18).

Acoustic impedance tests are widely used for hearing assessment (19), and provide information regarding the mobility of the tympanossicular system via external auditory canal pressure (tympanometry) and the contraction of the stapedius muscle through high-intensity sound stimulation (stapedial reflex) (20). In our study, stapedial reflex thresholds were elicited at normal intensities both in the patient and control groups, however there was statistically significant difference between PsA group and control group as for acoustic reflex at $4000 \mathrm{~Hz}$. The elevation or absence of stapedial reflex threshold may indicate a middle-ear dysfunction, cochlear hearing loss, retrocochlear pathology, and dysfunction in the facial nerve, and also help to interpret the audiological results. The stapedial reflex is not measurable in ears with conductive hearing loss. In the absence of conductive hearing loss, stapedial reflex thresholds can help to predict the degree and contour of cochlear pathology (21).

Tympanometric investigations provide information about abnormalities of the tympanic membrane (i.e., perforation, retraction, scarring), tympanum (middle ear effusion), and eustachian tube function (22). We compared tympanometric values as for compliance and pressure values an there was a statistically significant difference compared to control group.

In Amor-Dorado and colleagues' study, SRT and SD values were compared with those of the control groups and only SRT values were found to be significantly different from the patient group. As an outcome of this study, the authors concluded that SRT can be an important criterion in the evaluation of degree and type of the hearing loss and detection of the presence of cochlear dysfunction (17). However, in our study, SRT and SD values were not significantly different when compared with the control group.

In our study there was no significant correlation between inner ear functions and disease activity however, there was statistically significant positive correlation between disease severity (PASI) and both acoustic refex and bone conduction .

The limitations of the study were that our PsA patients were on treatment at the time of measurements, but both methotrexate and biological agents are not definitive ototoxic drugs though. Since PsA is a relatively rare diagnosis, it was not possible to recruit patients who had not received any treatment. Another limitation was the small number of patients recruited in the study.

In conclusion, significant differences in the pure-tone audiogram values at 8000 $\mathrm{Hz}$ and acoustic reflex at $4000 \mathrm{~Hz}$ were detected in patients with PsA. Also tympanometric values were statistically different relative to control group. Our study provides evidence suggesting the necessity of monitoring these patients regarding sensorineural hearing loss so as to take measures against the development of hearing loss during early stage, which may be another disability in patients with PsA, which is in itself a potential cause of severe disability.

\section{Declaration of interest}

The authors report no conflicts of interest. The authors alone are responsible for the content and 
writing of the paper.

Funding information

None declared

\section{REFERENCES}

(1) Zuel-Fakkar N M, Kame M M l, Asaad M K, et al. (2010): A study of ApaI and TaqI genotypes of the vitamin $\mathrm{D}$ receptor in Egyptian patients with psoriasis. Clinical and Experimental Dermatology, vol 36: 355-359.

(2) Bowes J and Barton A, (2010): The genetics of psoriatic arthritis: lessons from genome-wide association studies. Discovery Medicine Journal. Sep;10(52):177-83.

(3) Filer C, Ho P, Smith R, et al. (2008): Investigation of association of the IL12b and IL23R genes with psoriatic arthritis. arthritis \& rheumatism, vol 58: 3705-3709

(4) Salaffi F, Ciapetti A, Carotti M, et al. (2014): "Disease Activity in Psoriatic Arthritis: Comparison of the Discriminative Capacity and Construct Validity of Six Composite Indices in a Real World," BioMed Research International, vol. 2014, Article ID 528105, 12 pages, 2014. https://doi.org/10.1155/2014/528105.

(5) Queiro-Silva R., Torre-Aloso J.C., Tinture-Eguren T., et al. (2004): the effect of HLA-DR antigens on the susceptibility to, and clinical expression of psoriatic arthritis. Scand $\mathbf{J}$ Rheumatol; 33:318-322.

(6) Williamson L , Dockerty JL , Dalbeth N et l., (2004) : Gastrointestinal disease and psoriatic arthritis . J Rheumatol 31:1469-1470.

(7) Peter MJ, Van der Host-Bruinsma IE , Dijkmans BA, et al., (2004) :cardiovascular risk profile for patients with spondyloarthropathies, particularly ankylosing spondylitis and psoriatic arthritis . Semin Arthritis Rheum ; 34:585-592.

(8) Tumiati B, Casoli P, Parmeggiani A (1997): Hearing loss in the sjogren syndrome. Ann Intern Med; 126:450-3.

(9) Giani T , Simonini G, Lunardi C, et al., ( 2006) : juvenile psoriatic arthritis and acquired sensorineural hearing loss in a teenager : is there an association? Clin Exp Rheumatol ; 24: 344-6.

(10) Taylor W, Gladman D, Helliwel $P$ et al., (2006) : classification criteria for psoriatic arthritis :development of new criteria from a large international study. Arthritis Rheum Aug;54(8):2665-73.

(11) Soliman, S. M., Fathalla, A. and Shehata, W. (1985): Development of the Arabic Staggered Spondiac Words (SSW) Test. Proceeding of the 8th Annual Ain Shams Congress, 2: 1220-1246.

(12) Soliman, S., (1976): Speech discrimination audiometry using-Arabic Phonetically-Balanced Words. Ain Shams Medical Journal, 27: 27-30.

(13) Turkiewicz AM and MorelandLW (2007): Psoriatic Arthritis Current concept on pathogenesis oriented therapeutic options. Arthritis Rheum ; 56:1051-66.

(14) Karabulut H, Karadag AS, Dagli M et al., (2010) :Investigation of hearing and outer hair cell function of cochlea in patients with psoriasis. Int Adv Otol;6:239-44.

(15)Sonbay ND, Saka C, Tatlican S et al., (2014) : Audiological evaluation in patients with Behc,et's disease. J LaryngolOtol ;128:694-7.

(16)Landegger LD , Psaltis D, Stankovic KM (2016) : Human audiometric thresholds do not predict specific cellular damage in the inner ear". Hearing Research. 335: 83-93

(17)Amor-Dorado JC, BarreiraFernandez MP, Pina $T$ et al., (2014): Investigations into audiovestibularmanifestations in patients with psoriatic arthritis. $\mathbf{J}$ Rheumatol;41:2018-26.

(18)Akif Gunes a, Ibrahim Gundogdu b, Murad Mutlu c et al., (2016): Functions of the inner ear in psoriatic arthritis, Auris Nasus Larynx 43 (2016) 626-631

(19)Lide'n G (1980) : Impedance audiometry. Ann Otol Rhinol Laryngol Suppl ;89:53-8.

(20)Emanuel DC, Henson OEC, Knapp RR (2012) : Survey of audiologicalimmittance practices. Am J Audiol ;21:60-75.

(21)Hall J (1978) : Predicting hearing level from the acoustic reflex: a comparison of three methods. Arch Otolaryngol;104:602-5.

(22)Lilly D (1984) : Multiple frequency, multiple component tympanometry: new approaches to an old diagnostic problem. Ear Hear;5:300-8

To cite this article: Ahmed HN, Shehata OZ, Mekki SA, Hammad M. Assessment Of Subclinical Inner Ear Dysfunction In Psoriatic Arthritis Patients.,Egypt.ZUMJ 2019;25(3);401-408,DOI: 10.21608/zumj.2019.9579.1054 